\title{
A face feminina na linha de frente contra a pandemia de COVID-19
}

RESUMO | Objetivo: Refletir sobre as questões de gênero que permeiam o exercício da Enfermagem no Brasil no contexto da pandemia. Método: Trata-se de ensaio teórico do tipo reflexivo, que utiliza dados da pesquisa "Condições de Trabalho dos Profissionais de Saúde no Contexto da Covid-19" associados à contextualização histórica e sociológica da profissão. Resultados: As mulheres respondem por $70 \%$ dos recursos humanos em Saúde e $85 \%$ das equipes de Enfermagem no Brasil, profissão historicamente feminina. A pandemia teve impacto negativo para 95\% dos trabalhadores da Saúde, potencializado pela dupla jornada e cuidado com dependentes, no caso das mulheres. Conclusão: A redução da desigualdade entre as profissões e os gêneros é um caminho necessário em busca de mais respeito e reconhecimento profissional.

Palavras-chaves: Enfermagem; Pandemia; COVID-19; Saúde; Desigualdade.

ABSTRACT | Objective: To reflect on the gender issues that permeate the practice of Nursing in Brazil in the context of the pandemic. Method: This is a reflective theoretical essay, which uses data from the research "Working Conditions of Health Professionals in the Context of Covid-19" associated with the historical and sociological context of the profession. Results: Women account for $70 \%$ of health human resources and $85 \%$ of nursing teams in Brazil, a historically female profession. The pandemic had a negative impact on $95 \%$ of health workers, enhanced by the double shift and care for dependents, in the case of women. Conclusion: The reduction of inequality between professions and genders is a necessary path in search of more respect and professional recognition.

Keywords: Nursing; Pandemic; COVID-19; Health; Inequality.

RESUMEN | Objetivo: Reflexionar sobre las cuestiones de género que permean la práctica de Enfermería en Brasil en el contexto de la pandemia. Método: Se trata de un ensayo teórico reflexivo, que utiliza datos de la investigación "Condiciones laborales de los profesionales de la salud en el contexto del Covid-19" asociados al contexto histórico y sociológico de la profesión. Resultados: Las mujeres representan 70\% de los recursos humanos de salud y $85 \%$ de los equipos de enfermería en Brasil, una profesión históricamente femenina. La pandemia tuvo un impacto negativo en $95 \%$ de los trabajadores de salud, potenciado por el doble turno y la atención a las personas dependientes, en el caso de las mujeres. Conclusión: La reducción de la desigualdad entre profesiones y géneros es un camino necesario en busca de mayor respeto y reconocimiento profesional.

Palabras claves: Enfermería; Pandemia; Covid-19; Salud; Desigualdad.

\section{Betânia Maria Pereira dos Santos}

Enfermeira, doutora em Medicina e Saúde. Presidente do Conselho Federal de Enfermagem (Cofen). Conselho Federal de Enfermagem - Cofen. Brasília, DF, Brasil. Universidade Federal da Paraíba. João Pessoa, PB, Brasil.

ORCID: 0000-0002-7916-1995

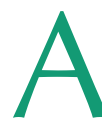
palavra pandemia, ao que tudo indica, não está no feminino por acaso. A enfermagem é feminina. A linha de frente no combate à COVID-19 revela o rosto de milhares de mulheres. São elas a maioria, as mais afetadas e as mais sobrecarregadas na crise sanitária que assola o mundo e se agrava de maneira trágica, sem precedentes, no Brasil.

O feminino está associado ao que se entende por cuidado. Do latim "cogitare e cura", a expressão se refere a ação de proporcionar bem estar físico e emocio- nal. Nos primeiros anos de vida, na doença e na convalescência, no envelhecimento e na morte, há sempre uma figura feminina, forte, presente.

Historicamente a enfermagem é uma profissão repleta de faces femininas. De Florence Nightingale, precursora no cuidado de feridos em batalhas, na Inglaterra do século 19, à Anna Nery, pioneira da enfermagem no Brasil, socorrendo soldados durante a Guerra do Paraguai, as muIheres desempenharam um papel fundamental na consolidação dos fundamentos da enfermagem contemporânea ${ }^{1}$.

No mundo, assim como no Brasil, a representatividade das mulheres na saúde segue aumentando: elas respondem por cerca de $70 \%$ das equipes de profissionais de saúde e quase $85 \%$ da força de trabalho na enfermagem ${ }^{2}$. Dos 2.452.264 de profissionais de enfermagem registrados nos Conselhos de Enfermagem ${ }^{3}$, estima-se que $50 \%$ estão na linha de frente do combate à COVID-19. Ou seja, cerca de 1 milhão de mulheres arriscam suas vidas diariamente na guerra contra o coronavírus. Os números refletem ainda o perfil feminino e negro da profissão: 53\% são negras (pretas e pardas).

O recente estudo Condições de Trabalho dos Profissionais de Saúde no Contexto da COVID-19, realizado pela Fiocruz com apoio do COFEN ${ }^{4}$, em todo o território nacional, divulgado em março de 2021, confirma que a força de trabalho é majoritariamente feminina $(77,6 \%)$ também entre os profissionais de nível superior, objeto desta etapa da pesquisa. A maior parte da equipe é de enfermeiros $(58,8 \%)$, seguida pelos médicos $(22,6 \%)$, fisioterapeutas $(5,7 \%)$, odontólogos (5,4\%) e farmacêuticos $(1,6 \%)$, com as demais profissões correspondendo a 5,7\%. Importante sublinhar que cerca de $25 \%$ deles foram infectados pela COVID-19. 
A pesquisa destaca que a pandemia alterou de modo significativo a vida de 95\% desses trabalhadores. Para pior. "Após um ano de caos sanitário, a realidade desses profissionais é marcada pela dor, sofrimento e tristeza, com fortes sinais de esgotamento físico e mental. O medo da contaminação e da morte acompanham seu dia a dia, em gestões marcadas pelo risco de perdas de direitos trabalhistas, salários baixos, gastos extras com EPIs, transporte alternativo e alimentação", detalhou a coordenadora do estudo, Maria Helena Machado.

O Fundo de População das Nações Unidas (UNFPA) também tem alertado para a acentuação das desigualdades de gênero e a piora da qualidade de vida das mulheres. Um impacto importante, na pandemia, é na jornada doméstica. As mulheres são quase sempre arrimos de suas famílias, criando filhos sozinhas e cuidando de parentes idosos ou enfermos. Gastam horas no transporte público para ir e voltar do trabalho, acumulam plantões e, no pouco que sobra, ainda cozinham e limpam a casa, quando deveriam descansar ${ }^{5}$.

Muitas mães têm ainda se afastado dos seus filhos e ficam em distanciamento social após o período de trabalho, para protegê-los do vírus, fazendo com que a vulnerabilidade psíquica seja maior para essas mulheres ${ }^{6}$.

Neste cenário povoado de heroínas, a pandemia expôs ao mundo uma desi-

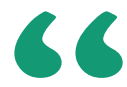

\section{Muitas mães têm ainda se afastado dos seus filhos e ficam em distanciamento social após o período de trabalho, para protegê-los do vírus, fazendo com que a vulnerabilidade psíquica seja maior para essas mulheres.}

gualdade que não pode mais ser ignorada. A essencialidade da enfermagem deve ser reconhecida pela sociedade e seus representantes na materialização de condições dignas de trabalho, com respaldo legal, que propiciem qualidade de vida. A crise impõe a necessidade de ações simultâneas de atendimento emergencial e planejamento, com um olhar atento às questões de gênero.

O que é essencial, na sociedade, vem sendo ressignificado. A urgência por melhores condições de trabalho e salários dignos estampam a face feminina da linha de frente do combate ao coronavírus. A valorização da atuação dessas mulheres ainda não se materializou como direitos fundamentais. Um bom começo é somar os governantes e população no apoio às reivindicações já realizadas pela classe ${ }^{7}$.

A redução da desigualdade entre as profissões e os gêneros é um caminho necessário em busca de mais respeito e reconhecimento profissional. A luta dessas mulheres, que carregam a representatividade de todo um gênero, deve ser uma luta de todos. Assim, a vitória será delas e de toda a população.

Enquanto o mundo prolifera a frase "fique em casa", as mulheres da linha de frente da pandemia apenas querem voltar para casa, mesmo com suas faces marcadas, com a missão cumprida, e a esperança de que dias melhores virão.

\section{Referências}

1. Conselho Federal de Enfermagem (Cofen). Biblioteca Virtual. Florence Nightingale - História da Enfermagem. [Internet]. 2021 [acessado 2021 Mar 20]. Disponível em: http://biblioteca.cofen.gov.br/florence-nightingale-historia-da-enfermagem/.

2. Machado MH [Coordenadora]. Pesquisa Perfil da Enfermagem no Brasil: Relatório Final. Rio de Janeiro: Nerhus-Daps-Ensp/Fiocruz; 2017 [acessado 2021 Mar 22]. Disponível em:

http://www.cofen.gov.br/perfilenfermagem/pdfs/relatoriofinal.pdf. 3. Conselho Federal de Enfermagem (Cofen). Enfermagem em Números [Internet]. [acessado 2021 Mar 26]. Disponível em: http://www.cofen. gov.br/enfermagem-em-numeros.

4. Agência Fiocruz de Notícias. Covid-19: Estudo avalia condições de trabalho na Saúde [Internet]. 2020 [acessado 2021 Mar 22]. Disponível em: https://agencia.fiocruz.br/covid-19-estudo-avalia-condicoes-detrabalho-na-saude.
5. Revista Marie Claire. Quem cuida dos filhos das enfermeiras durante a pandemia? [Internet]. 2019 [acessado 2021 Mar 20]. Disponível em: https://revistamarieclaire.globo.com/Mulheres-do-Mundo/noticia/2020/05/quem-cuida-dos-filhos-das-enfermeiras-durante-pandemia.html.

6. Folha de S. Paulo. Mulheres criam filhos, acumulam plantões e limpam a casa na folga [Internet]. 2021 [acessado 2021 Mar 20]. Disponivel em: https://www1.folha.uol.com.br/colunas/drauziovarella/2021/03/mulheres-criam-filhos-sozinhas-acumulam-plantoes-e-limpam-a-casa-na-folga.shtml? origin=folha.

7. Cunha I.C.K.O, \& Freire NP. (2020). 0 que é essencial para os profissionais essenciais?. Enfermagem em Foco, 11(2.ESP). [acessado 2021 Mar 18] Disponivel em: http://revista.cofen.gov.br/index.php/enfermagem/article/view/4156/842. 